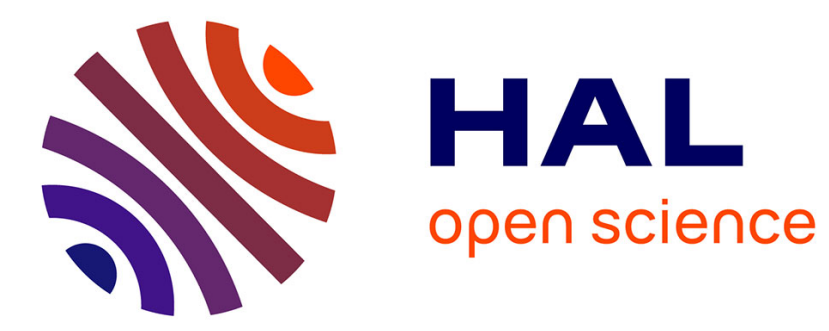

\title{
Heart Failure with preserved Ejection Fraction: Defining phenotypes
}

\author{
Erwan Donal, Guillaume L'Official, W Kosmala
}

\section{To cite this version:}

Erwan Donal, Guillaume L'Official, W Kosmala. Heart Failure with preserved Ejection Fraction: Defining phenotypes. Journal of Cardiac Failure, 2020, 26 (11), pp.929-931. 10.1016/j.cardfail.2020.09.013 . hal-02959058

\section{HAL Id: hal-02959058 https://hal.science/hal-02959058}

Submitted on 18 Nov 2020

HAL is a multi-disciplinary open access archive for the deposit and dissemination of scientific research documents, whether they are published or not. The documents may come from teaching and research institutions in France or abroad, or from public or private research centers.
L'archive ouverte pluridisciplinaire HAL, est destinée au dépôt et à la diffusion de documents scientifiques de niveau recherche, publiés ou non, émanant des établissements d'enseignement et de recherche français ou étrangers, des laboratoires publics ou privés. 


\section{Heart Failure with preserved Ejection Fraction: Defining phenotypes}

Erwan DONAL ${ }^{1}$, Guillaume L'OFFICIAL ${ }^{1}$, Wojciech KOSMALA ${ }^{2}$

1. University of Rennes, CHU Rennes, Inserm, LTSI - UMR 1099, F-35000 Rennes, France

2. Cardiology Department, Wroclaw Medical University, Wroclaw, Poland

\section{Conflict of interest:}

There are no commercial products involved in this study.

\section{Correspondence}

Erwan Donal, MD, PhD,

Service de Cardiologie - Hôpital Pontchaillou - CHU Rennes-

\section{F-35033 RENNES}

erwan.donal@chu-rennes.fr

Fax: +33299282510 
Heart failure with preserved ejection (HFpEF) has been increasingly recognized as an epidemic and various phenotypes have now been suggested (1). The clinical presentation as well as medical history may vary in this condition. Some patients experience multifold hospitalizations, and others complain of breathlessness and have a similar decrease in quality of life, but have never been hospitalized. Some patients have severe, recurrent congestion, and others are essentially symptomatic only when exercising.

The modern concept of HFpEF was proposed by Luchi et al., who in 1982 described a group of patients with typical heart failure symptoms associated with preserved ( $\geq 50 \%)$ left ventricular ejection fraction (LVEF) (2). The heterogeneity of this syndrome was one of the reasons that several randomized studies using simple criteria did not provide evidence for effective therapies, and over the years, being wiser with the experience from these trials, we are seeking treatment strategies that could be phenotype specific for a segment of the HFpEF population (35). The array of tested remedies is quite vast and still increasing, including both pharmacological agents and implantable devices (6).

Recently, HFpEF has been re-defined by the European Society of Cardiology (ESC) as preserved left ventricular EF (LVEF $\geq 50 \%$ ), with evidence of diastolic dysfunction and structural heart disease, in the context of elevated biomarkers, and classic signs and symptoms of heart failure (1). The importance of echocardiography and dynamic testing is reflected in the score that is the essence of the proposed diagnostic algorithm (7). By using a comprehensive, alternative-based evaluation process, this new approach improves the accuracy of HFpEF identification, and probably is more effective in identifying the "never-hospitalized" patients who are complaining mainly of exertional dyspnea. On the other hand, it does not permit a priori stratification of 
patients according to the occurrence and severity of symptoms. Other scores and pathophysiologically-based diagnostic approaches have been proposed, but their relevance in the context of patient selection for interventions providing symptomatic and prognostic improvement has not been validated (8-10).

The manuscript by Reddy et al in the current issue of the Journal deserves special attention and careful analysis (11). It is based on $7 \mathrm{NIH}$ sponsored multicenter trials in HFpEF and focuses on the distinction between patients with and without HF hospitalization. The hospitalization phenotype is characterized by a larger burden of non-cardiac pathologies including more advanced renal dysfunction, COPD and anemia, more impaired functional capacity and worse outcomes. Interestingly, the quality of life and resting echocardiographic profile are similar in both subsets stratified on the basis of hospitalization history. Nevertheless, these observations might suggest that the 2 categories may require different management approaches, with multiorgan protection and prevention of recurrent congestion in the "hospitalized" group vs. a focus on improving exercise capacity in the "never-hospitalized" subset.

The authors emphasize that it is not clear whether these 2 groups of patients represent the same disease process at different stages or different clinical phenotypes (figure 1). A potential transition from the less-diseased to the more-diseased HFpEF category was previously postulated but is not proven (12). As a consequence, if the contribution from the non-cardiac organs to the disease process is not a distinctive feature of the "hospitalized" phenotype, approaches that prevent the progression of extra-cardiac pathologies should be considered in patients with HFpEF who have never experienced a HF hospitalization. As a consequence in 
might be important to search for the common denominator contributing to the progression of multi-organ abnormalities e.g. systemic inflammation (13).

The current paper is a retrospective, multi-trial analysis, in which the extent of echocardiography use was limited by the protocols of the original studies. It is likely that the inclusion of additional echocardiographic parameters, especially LV and LA strain, and RV/pulmonary indices, might have improved the characterization of clinically-derived phenotypes and provided more information relevant for decision-making. Furthermore, an important source of prognostic data in patients without HF hospitalization would have been exercise echocardiography, with quantification of LV diastolic and systolic responses to exertion. Accordingly, extended imaging might add to the "macroscopic" phenotyping proposed by Reddy et al $(11,14)$.

Despite this limitation, the results set the stage for further studies. What were the results of PARAGON -HF in non-hospitalized patients(15)? Given the vasodilating properties of sacubitril/valsartan, this treatment could be more beneficial in patients who need more afterload reduction than a decrease in fluid retention. The relative and absolute benefits of sacubitril/valsartan compared with valsartan alone in HFpEF appear to be amplified when initiated in the high-risk window after hospitalization. On the other hand, patients hospitalized or recently hospitalized might require a more aggressive diuresis by agents that are safe for the kidney and liver like the gliflozins (16). Accordingly, the work by Reddy et al. may facilitate the interpretation of trial findings and provide guidance on specific treatment approaches (11). 
Another issue that needs to be addressed is the clinical impact of atrial fibrillation, as well as the approaches to the management of this arrhythmia in both HF hospitalization-based phenotypes. The presence of atrial fibrillation may be an important component of the phenotypic profiling in HFpEF and should be taken into account when planning therapeutic strategies (17).

To summarize, the current contribution underscores once again the need for phenotype-specific therapy in patients categorized as having HFpEF. The presence of HF hospitalization in the patient history is a powerful determinant of the clinical presentation and outcome. The putative pathophysiological differences between patients with HFpEF with and without HF hospitalizations need to be more profoundly explored in future studies. The potential therapeutic implications of this approach to HFpEF heterogeneity based on the history of HF hospitalization might be worth considering to improve patient management. We believe that the wider use of echocardiography in the phenotyping process may aid in establishing efficient treatments in this highly prevalent condition. 


\section{References}

1. Pieske B, Tschope C, de Boer RA, Fraser AG, Anker SD, Donal E, et al. How to diagnose heart failure with preserved ejection fraction: the HFA-PEFF diagnostic algorithm: a consensus recommendation from the Heart Failure Association (HFA) of the European Society of Cardiology (ESC). Eur Heart J. 2019;40(40):3297-317.

2. Luchi RJ, Snow E, Luchi JM, Nelson CL, Pircher FJ. Left ventricular function in hospitalized geriatric patients. J Am Geriatr Soc. 1982;30(11):700-5.

3. Solomon SD, McMurray JJV, Anand IS, Ge J, Lam CSP, Maggioni AP, et al. Angiotensin-Neprilysin Inhibition in Heart Failure with Preserved Ejection Fraction. N Engl J Med. 2019;381(17):1609-20.

4. Pitt B, Pfeffer MA, Assmann SF, Boineau R, Anand IS, Claggett B, et al. Spironolactone for heart failure with preserved ejection fraction. N Engl J Med. 2014;370(15):1383-92.

5. Pieske B, Maggioni AP, Lam CSP, Pieske-Kraigher E, Filippatos G, Butler J, et al. Vericiguat in patients with worsening chronic heart failure and preserved ejection fraction: results of the SOluble guanylate Cyclase stimulatoR in heArT failurE patientS with PRESERVED EF (SOCRATES-PRESERVED) study. Eur Heart J. 2017;38(15):1119-27.

6. Silverman DN, Shah SJ. Treatment of Heart Failure With Preserved Ejection Fraction (HFpEF): the Phenotype-Guided Approach. Curr Treat Options Cardiovasc Med. 2019;21(4):20.

7. Shah AM, Cikes M, Prasad N, Li G, Getchevski S, Claggett B, et al. Echocardiographic Features of Patients With Heart Failure and Preserved Left Ventricular Ejection Fraction. J Am Coll Cardiol. 2019;74(23):2858-73.

8. Shah AM, Claggett B, Sweitzer NK, Shah SJ, Anand IS, O'Meara E, et al. Cardiac structure and function and prognosis in heart failure with preserved ejection fraction: findings from the echocardiographic study of the Treatment of Preserved Cardiac Function Heart Failure with an Aldosterone Antagonist (TOPCAT) Trial. Circ Heart Fail. 2014;7(5):740-51.

9. Senni M, Paulus WJ, Gavazzi A, Fraser AG, Diez J, Solomon SD, et al. New strategies for heart failure with preserved ejection fraction: the importance of targeted therapies for heart failure phenotypes. Eur Heart J. 2014;35(40):2797-815.

10. Selvaraj S, Myhre PL, Vaduganathan M, Claggett BL, Matsushita K, Kitzman DW, et al. Application of Diagnostic Algorithms for Heart Failure With Preserved Ejection Fraction to the Community. JACC Heart Fail. 2020;8(8):640-53.

11. Reddy Y N V OM, Jones A, Lewis, G, Shah S, AbouEzzeddine O F, Fudim M, Alhanti B, Stevenson L, Redfiled $\mathrm{M}$, Borlaug $\mathrm{B} A$. Characterization of the progression from ambulatory to hospitalized heart failure with preserved ejection fraction. Jour Cardiac Failure. 2020;in press.

12. Kosmala W, Rojek A, Przewlocka-Kosmala M, Mysiak A, Karolko B, Marwick TH. Contributions of Nondiastolic Factors to Exercise Intolerance in Heart Failure With Preserved Ejection Fraction. J Am Coll Cardiol. 2016;67(6):659-70.

13. Donal E, Lund LH, Oger E, Reynaud A, Schnell F, Persson H, et al. Value of exercise echocardiography in heart failure with preserved ejection fraction: a substudy from the KaRen study. Eur Heart J Cardiovasc Imaging. 2016;17(1):106-13.

14. Donal E, Lund LH, Oger E, Bosseau C, Reynaud A, Hage C, et al. Importance of combined left atrial size and estimated pulmonary pressure for clinical outcome in patients presenting with heart failure with preserved ejection fraction. Eur Heart J Cardiovasc Imaging. 2017.

15. Vaduganathan M, Claggett BL, Desai AS, Anker SD, Perrone SV, Janssens S, et al. Prior Heart Failure Hospitalization, Clinical Outcomes, and Response to Sacubitril/Valsartan Compared With Valsartan in HFpEF. J Am Coll Cardiol. 2020;75(3):245-54. 
16. McMurray JJV, DeMets DL, Inzucchi SE, Kober L, Kosiborod MN, Langkilde AM, et al. The Dapagliflozin And Prevention of Adverse-outcomes in Heart Failure (DAPA-HF) trial: baseline characteristics. Eur J Heart Fail. 2019;21(11):1402-11.

17. Kosmala W. Heart Failure With Preserved Ejection Fraction and Atrial Fibrillation: How to Fight Allied Enemies. J Am Coll Cardiol. 2020;76(9):1065-7.

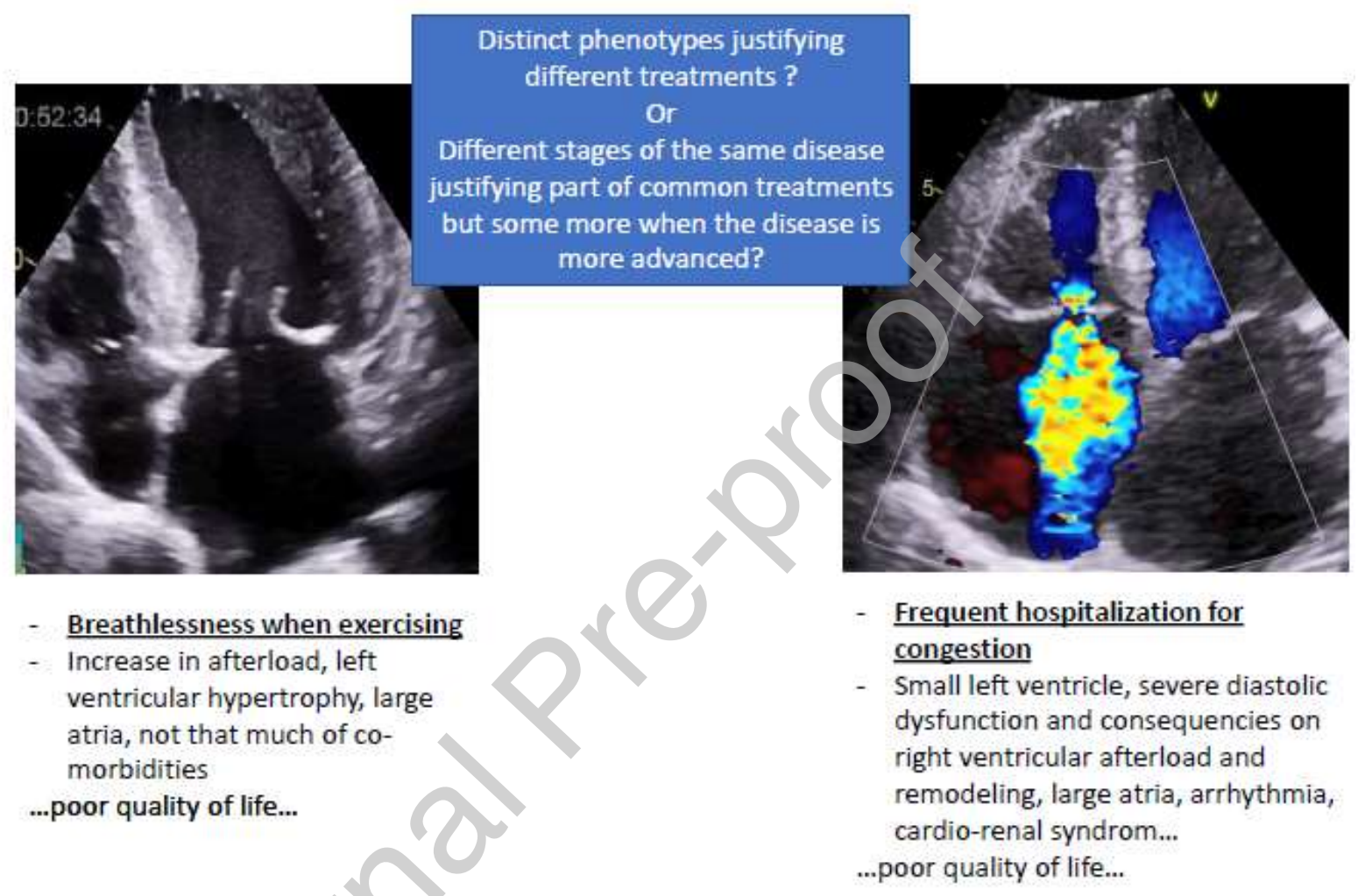

Figure 1: two phenotypes with distinct pathophysiology or two stage of the same disease? 